Original Article

\title{
Comparison of sleep-wake rhythms in elderly persons with intellectual disabilities and the general population
}

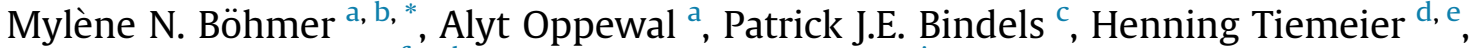 \\ Eus J.W. van Someren ${ }^{\mathrm{f}, \mathrm{g}, \mathrm{h}}$, Dederieke A.M. Festen ${ }^{\text {a, i }}$ \\ a Erasmus MC, University Medical Center Rotterdam, Department of General Practice, Intellectual Disability Medicine, the Netherlands \\ ${ }^{\mathrm{b}}$ Middin, Care Organization for People with Intellectual Disabilities, Rijswijk, the Netherlands \\ ${ }^{\mathrm{c}}$ Erasmus MC, University Medical Center Rotterdam, Department of General Practice, the Netherlands \\ d Erasmus MC, University Medical Center Rotterdam, Department of Epidemiology, the Netherlands \\ e Department of Social and Behavioral Sciences, Harvard. T.H. Chan School of Public Health, Boston, MA, USA \\ ${ }^{\mathrm{f}}$ Department of Sleep and Cognition, Netherlands Institute for Neuroscience, An Institute of the Royal Netherlands Academy of Arts and Sciences, \\ Amsterdam, the Netherlands \\ ${ }^{\mathrm{g}}$ Vrije Universiteit, Department of Integrative Neurophysiology, Centre for Neurogenomics and Cognitive Research, Neuroscience Campus Amsterdam, \\ Amsterdam, the Netherlands \\ h Amsterdam UMC, Vrije Universiteit, and GGZ InGeest, Dept. of Psychiatry, Amsterdam Public Health Research Institute, Amsterdam, the Netherlands \\ i Ipse de Bruggen, Care Organization for People with Intellectual Disabilities, Zoetermeer, the Netherlands
}

\section{A R T I C L E I N F O}

\section{Article history:}

Received 13 July 2020

Received in revised form

30 September 2020

Accepted 16 October 2020

Available online 21 October 2020

\section{Keywords:}

Actigraphy

Circadian rhythm

Sleep

Aging

Older adults

Intellectual disability

\begin{abstract}
A B S T R A C T
Background: Sleep problems are common in people with intellectual disabilities (ID), but the knowledge on the natural course of sleep-wake rhythms and sleep problems in elderly persons with ID is limited. In the current study, objectively measured sleep-wake rhythms and the prevalence and severity of sleep problems of elderly persons with ID was compared to that of healthy elderly persons from a large representative sample from the general population.

Methods: Actigraphy data of 501 elderly persons with ID (age $62.02 \pm 8.02$ years, $48 \%$ female) from the Healthy Ageing and Intellectual Disabilities study was compared to the data of 1734 elderly persons from the general population (age $62.24 \pm 9.34$ years, 53\% female) from the Rotterdam Study. Main outcome variables were Interdaily stability (IS) and Intradaily variablitiy (IV), total sleep time (TST), Waking after sleep onset (WASO), Short sleep (TST $<6 \mathrm{~h}$ ), Night waking (WASO $>90 \mathrm{~min}$ ).

Results: Elderly persons with ID had less stable sleep wake rhythms than elderly persons from the general population ( $I S=0.70 \pm 0.17$, vs $0.80 \pm 0.10 \mathrm{z}=-8.00$ ). Their sleep-wake rhythm was also more fragmented (IV $=0.56 \pm 0.26$ vs $0.42 \pm 0.13$ respectively, $\mathrm{z}=8.00$ ). Elderly persons with ID slept on average $60.09 \mathrm{~min}$ longer than elderly persons from the general population, and lay awake $48.28 \mathrm{~min}$ longer after sleep onset. Short sleep in elderly persons with ID was less prevalent $(20.7 \%$ vs $30.2 \%)$ but more severe (TST in Short sleep; $5.13 \pm 0.80 \mathrm{~h}$ vs $5.39 \pm 0.50 \mathrm{~h}, \mathrm{z}=-2.76$ ) then in elderly persons from the general population. Night waking was more prevalent (63.0\% vs $17.7 \%$ ) and more severe in elderly persons with ID (WASO in Night waking; $150.39 \pm 54.72 \mathrm{~min}$ vs $111.60 \pm 17.95 \mathrm{~min}, \mathrm{z}=7.06$ ).

Conclusion: The differences in sleep-wake rhythms, prevalence and severity of sleep problems between elderly persons with and without ID are marked and possibly explained by medical, psychiatric conditions and lifestyle in elderly persons with ID. Better understanding of sleep in elderly with ID is needed to improve the quality of sleep in this population and to diminish health problems related to a disruption of sleep.
\end{abstract}

(c) 2020 Elsevier B.V. All rights reserved.

\footnotetext{
* Corresponding author. Erasmus MC, University Medical Center Rotterdam, Department of General Practice, Intellectual Disability Medicine, P.O. Box 2040, 3000 CA Rotterdam, the Netherlands.

E-mail address: m.bohmer@erasmusmc.nl (M.N. Böhmer).
}

\section{Introduction}

Sleep problems are common in people with intellectual disabilities (ID) [1]. These sleep problems include a long sleep latency, low sleep efficiency, night waking, and early waking $[1,2]$. These 
problems are typically present from childhood, and are considered to be persistent through adulthood [2,3]. However, little is known about the natural course of the sleep-wake rhythms and sleep problems at older age, as studies in elderly persons with ID are scarce $[4,5]$.

The only study on the sleep-wake rhythms of elderly persons with ID, the Healthy Ageing and Intellectual Disabilities study (HAID study), showed that the sleep-wake rhythms of 501 elderly persons with ID were less stable and more fragmented [6] when compared to a small sample of elderly persons from the general population $(n=50)$. Sleep is characterized by long time in bed, long night waking and a low sleep efficiency [7]. Seventy-two percent of elderly persons with ID presented with at least one sleep problem, of which the most common was night waking for more than $90 \mathrm{~min}$, with a prevalence of $63.1 \%$ [7]. It is unclear how these sleep estimates and sleep problems in elderly persons with ID differ from those seen in elderly persons from the general population.

In the general population the sleep-wake rhythms change with age. The sleep-wake rhythms become more fragmented [8], there is a tendency for earlier bed-and wake times, and the total sleep time shortens with age [9]. These changes in sleep-wake rhythms are the result of the age-related changes in the biological clock in the brain [10-12], that regulates the sleep-wake rhythms [13]. Aside from the age-related changes, sleep-wake rhythms in elderly persons can be disrupted as a result of medical and psychiatric comorbidities, like chronic pain, cardiovascular disease, depression and anxiety, and medication use [14]. In addition, one's lifestyle is also associated with the sleep-wake rhythms and sleep characteristics $[8,14]$.

In elderly persons with ID, multiple comorbidities and use of medication that influence sleep, as well as polypharmacy are more prevalent than in the general population [15-18]. In addition, an inactive lifestyle, living in a care facility and being dependent from care givers might also affect the sleep-wake rhythms in this population [6,7]. All these factors make elderly persons with ID more vulnerable for disruptions of sleep, in addition to the age-related changes seen in elderly persons from the general population. Insight in the specific sleep-wake rhythms and sleep problems in elderly persons with ID is a starting point in improving diagnosis and treatment of the specific sleep problems in this population.

The aims of this study are; (1) to compare sleep-wake rhythms of elderly with ID with that seen in elderly from the general population, and (2) to compare the prevalence and severity of sleep problems in elderly with ID and those in elderly from the general population.

\section{Methods}

\subsection{Participants}

\subsubsection{Elderly persons with intellectual disabilities}

Data on elderly persons with ID was obtained from the large cohort study 'Healthy Ageing and Intellectual Disabilities' (HA-ID) in the Netherlands, from which we used the cross-sectional baseline data. The HA-ID study is a collaboration between three care providers for people with ID in the Netherlands (Abrona, Amarant and Ipse de Bruggen) and the research group of Intellectual Disability Medicine at the Erasmus MC, University Medical Center Rotterdam. All elderly persons of 50 years and older $(n=2322)$ who received care from the collaborating care providers were invited to participate in the HA-ID study. A total of 1050 elderly persons were included in the study. Most of the participants of the HA-ID study (94.2\%) resided in a group home for people with ID where they receive care and/or support. An extensive description of the design, recruitment and measurements has been presented elsewhere [19].
The Medical Ethical Committee of the Erasmus MC provided ethical approval of the study (MEC 2008-234). Written informed consent was obtained from all participants or their legal representatives. Participants who would refuse to wear the measurement instruments, or were known to easily lose or break the measurement instruments were excluded from this study. Data on sleep-wake rhythms and sleep was collected between February 2009 and July 2010. Data of a total of 501 participants was available for the current study.

\subsubsection{Elderly from the general population}

Data on elderly persons from the general population was obtained from the Rotterdam Study, a population-based cohort study of older persons ( $>45$ years) which started in 1990 in the district of Ommoord, Rotterdam, the Netherlands. A complete description of the design of the Rotterdam Study is presented elsewhere [20]. The Rotterdam Study has been approved by the Medical Ethics Committee of the Erasmus MC (registration number MEC 02.1015) and by the Dutch Ministry of Health, Welfare and Sport (Population Screening Act WBO, license number 1071272-159521-PG). Written informed consent was obtained from all participants. Data on rhythms and sleep was collected from December 2004 to April 2007. Participants had to be able to understand the instructions, participants with considerable cognitive impairment (Mini-Mental State Examination, score $<22$ ) [21] were excluded from participation in the actigraphy study. A total of 2.632 participants were invited to participate, of whom 2.063 agreed. Data of a total of 1734 participants was available for the current study.

\subsection{Measurements}

\subsubsection{Assessment of the sleep-wake rhythms}

Both the HA-ID study and the Rotterdam Study used actigraphy, with the Actiwatch, to measure the sleep-wake rhythms and sleep. The Actiwatch is a wrist-worn accelerometer measuring movement activity by means of a piezo-electric accelerometer. The participants of the HA-ID study wore the Actiwatch 7 (Cambridge Technology Ltd, Cambridge, United Kingdom), participants from the Rotterdam study wore the Actiwatch 4 (Cambridge Technology Ltd, Cambridge, United Kingdom). The update between the two models did not affect the accelerometer and therefore the models are comparable. The Actiwatch is considered a valid and reliable measurement of the sleep-wake rhythms and sleep in adults from the general population [22] and in elderly persons with ID [23].

In the HA-ID study activity counts were set to sum activity counts for 1-min epochs, whereas the Rotterdam Study used epochs of $30 \mathrm{~s}$. Each study accounted for the epoch length when converting the raw data to the final outcome variables. Thus the different epoch lengths between the studies did not affect the comparability of the outcome variables. Both studies used the high sensitivity setting (20 counts per epoch), as this showed to be the most sensitive to detect wake $[23,24]$.

Participants of the HA-ID study wore the Actiwatch for 14 consecutive days on the non-dominant wrist. A measurement was considered valid if it provided at least seven days of usable data. In the Rotterdam Study, participants wore the Actiwatch for seven consecutive days and data was considered valid if it consisted of at least four days of usable data. The participants of the HA-ID study provided on average 12.98 days $(\mathrm{SD}=1.67$ days) of usable data, and the participants of the Rotterdam Study 5.75 days ( $\mathrm{SD}=0.58$ days). This difference is not considered relevant for the comparison of sleep estimates, as in elderly persons the means for sleep estimates have previously been found to remain consistent over using 3,7 and 14 days of data in the general population [25]. 
Based on the distribution of movement activity, sleep-wake rhythms parameters were calculated using non parametric rhythm analyses [26]. This analysis makes it possible to analyse the rhythms without assumptions on the distribution of the rhythms. The parameters of the rhythms of interest were interdaily stability (IS) and intradaily variability (IV). IS represents the stability of the sleep-wake rhythms. It ranges from 0 to 1 where 1 represents a perfect stable rhythm over the days. IV indicates the fragmentation of the rhythms. IV ranges between 0 and 2, where a higher score represents a more fragmented rhythm. The Relative Amplitude (RA) is calculated as the difference between the activity per hour of 10 most active hours (M10) and the 5 least active hours (L5) using the formula RA $=$ M10-L5/M10 + L5. High RA values result from greater daytime activity or reduced activity during sleep. RA scores range from 0 to 1 , with higher values indicating a rhythm with higher amplitude.

The Actiwatch software provides the sleep estimates total sleep time (TST, time asleep between sleep onset and final wake time) and waking after sleep onset (WASO, minutes awake between sleep onset and final wake time), an indicator of sleep quality. Based on the TST and WASO, the prevalence and severity of the sleep problems were estimated. Night waking was considered present at WASO $>90$ min $[27,28]$. A TST of $<6 \mathrm{~h}$ was considered short sleep $[7,29,30]$.

\subsubsection{Assessment of demographics, health indicators and lifestyle}

Selection of covariates was based on the previous work using actigraphy data in the Rotterdam Study and the HA-ID study [6-8]. Whenever the measurement of a covariate differed too much between studies, the covariate was excluded from the analysis. This was the case for anxiety and dementia; the HA-ID study screened for anxiety symptoms, whereas the Rotterdam Study diagnosed clinical anxiety disorders. The HA-ID study provided information on the prevalence of dementia, whereas the Rotterdam Study excluded people with dementia from participating in the actigraphy study. The final selected covariates were; age, sex, body mass index (BMI), smoking, ability to perform activities of daily living (ADL), scheduled daily activities and depressive symptoms.

In the HA-ID study, information on age and sex was extracted from the medical records. Body mass index (BMI) was calculated based on the measured height and weight $\left(\mathrm{kg} / \mathrm{m}^{2}\right)$ of the participants. Information on current smoking (yes/no), ADL and scheduled daily activities was provided by the professional caregiver. The ability to perform basic ADL was assessed with the Barthel Index [31] that the professional caregiver filled out. Participants who took part in organized daily activities on a regular basis, scored yes on scheduled daily activities (yes/no).

Participants of the HA-ID study were screened for depressive symptoms using two screening instruments [32]. For participants capable of self-report, the Inventory of Depressive Symptomatology Self Report (IDS-SR) was used, with a cut-off score of 18 for depressive symptoms [33]. The Dutch Signalizing Depression List for people with Intellectual Disabilities (SDL-ID) was used for participants with insufficient cognitive or verbal capacities to complete self-report [34], the cut-off score of 35 defined participants with clinically relevant depressive symptoms [35]. If a participant scored above the cut-off on one of these instruments, the participant was classified as having depressive symptoms (yes/ no).

In the Rotterdam-study, participants were visited for a home interview during which sex, age, current smoking (yes/no) and scheduled daily activities (yes/no) was assessed. Participants received a yes if they were employed. The ability to perform ADL score was assessed using the Stanford Health Assessment Questionnaire [36]. Depressive symptoms (yes/no) were assessed with the Center for Epidemiologic Studies Depression (CES-D) [37], with a cut-off score of 16 to define clinically relevant depressive symptoms [38].

For the purpose of describing the study populations, medication use was extracted from the medical files of the participants in both studies and by cabinet check in the Rotterdam Study. Medications known to or suspected to affect the sleep-wake rhythms or sleep were: antileptics (yes/no), psycholeptics (yes/no) and psychoanaleptics (yes/no). In order to describe the study sample of the HAID study, level of ID was included in the dataset. Level of ID was obtained from behavioural therapists' records, and was classified as borderline (IQ 70-85), mild (IQ 55-70), moderate (IQ 35-55), severe (IQ 25-35) or profound (IQ < 25).

\subsection{Statistical analysis}

Prior to analysis, ADL scores and level of ID were transformed. Because the studies used different instruments for the ADL score, the scores were transformed to percentages ranging between 0 and 100 , in which a lower percentage indicating a better ability to perform ADL. Level of ID was described for the participants of the HA-ID study, participants of the Rotterdam Study were categorized as "no ID".

In order to handle outliers, sleep-wake rhythm- and sleep parameters were winsorized at three standard deviations from the mean. Missing data on covariates (ADL; $12.9 \%$ missing data; all other covariates $<5 \%$ missing data) were imputed using 5 -fold multiple imputation, based on group, covariates and outcome variables.

First, the demographics, health indicators and lifestyle were analysed for possible differences between the two groups, and between HA-ID participants who provided both sleep-wake rhythms and sleep estimates and HA-ID participants who provided only data on sleep-wake rhythms. Continuous variables ware analysed using t-test, categorical variables with chi-square test.

We assessed the possible group differences in IS, IV, RA, L5, M10, TST and WASO using linear regression analyses. In the first step the variable group (Rotterdam Study: 0; HA-ID; 1 ) was added, in the second step we corrected for sex, age, daily activities, ADL score, BMI, current smoking, and depressive symptoms. The explained variance and confidence interval for the variable group is presented. The group differences for prevalence of sleep problems was assessed in a logistic regression analysis correcting for the same covariates. To study the severity of sleep problems between the two populations, linear regression analyses for TST and WASO was conducted in participants with night waking or short sleep.

Analyses were performed using SPSS statistics (version 25).

\section{Results}

\subsection{Participant characteristics}

The dataset of the HA-ID study consisted of 501 participants with actigraphy data, of which 300 participants also provided data for the comparison on the sleep variables. The dataset of the Rotterdam Study consisted of 1734 participants with actigraphy data for the sleep-wake rhythm analysis, of which data of 1728 participants was also available for the comparison of sleep estimates.

Table 1 describes the characteristics of the elderly persons with ID and elderly persons from the general population. Elderly persons with ID and elderly persons from the general population did not differ in age, sex, BMI and current smoking status. The majority of participants with an ID (84\%) had a borderline to moderate intellectual disability. Participants with ID scored more often above cut off for depressive symptoms (15\% vs $9 \%$ ), were more dependent in 
Table 1

Demographics, health indicators and lifestyle characteristics of elderly persons with ID and elderly persons from the general population.

\begin{tabular}{|c|c|c|c|}
\hline & $\begin{array}{l}\text { Elderly persons with } \\
\text { intellectual disabilities } \\
\mathrm{n}=501\end{array}$ & $\begin{array}{l}\text { Elderly persons from } \\
\text { general population } \\
\mathrm{n}=1734\end{array}$ & $p$-value ${ }^{a}$ \\
\hline \multicolumn{4}{|l|}{ Demographics } \\
\hline Female, (count, \%) & $249(48 \%)$ & $926(53 \%)$ & 0.16 \\
\hline Age, years (mean, sd) & $62.02(8.02)$ & $62.24(9.34)$ & 0.62 \\
\hline \multicolumn{4}{|l|}{ Level of Intellectual disability, (count, \%) } \\
\hline Borderline & $25(5 \%)$ & & \\
\hline Mild & $127(25 \%)$ & & \\
\hline Moderate & $266(53 \%)$ & & \\
\hline Severe & $48(10 \%)$ & & \\
\hline Profound & $26(5 \%)$ & & \\
\hline \multicolumn{4}{|l|}{ Health indicators } \\
\hline ADL score, (mean, sd) & $27.27(26.94)$ & $11.20(16.40)$ & $<\mathbf{0 . 0 0 1}$ \\
\hline Depressive symptoms, (count, \%) & $73(15 \%)$ & $153(9 \%)$ & $<\mathbf{0 . 0 0 1}$ \\
\hline Use of Antiepileptics, (count, \%) & $90(18 \%)$ & $25(1 \%)$ & $<\mathbf{0 . 0 0 1}$ \\
\hline Use of Psycholeptics, (count, \%) & $147(29 \%)$ & $184(11 \%)$ & $<\mathbf{0 . 0 0 1}$ \\
\hline Use of Psychoanaleptics, (count, \%) & $50(10 \%)$ & $108(6 \%)$ & 0.01 \\
\hline \multicolumn{4}{|l|}{ Lifestyle } \\
\hline BMI, (mean, sd) & $27.73(5.20)$ & $27.86(4.16)$ & 0.58 \\
\hline Current smoking, (count, \%) & $116(23 \%)$ & $362(21 \%)$ & 0.27 \\
\hline Scheduled daily activities, (count, \%) & $460(92 \%)$ & $574(33 \%)$ & $<0.001$ \\
\hline
\end{tabular}

Abbreviation: SD, standard deviation.

a $\mathrm{t}$-test for continues variables, chi-square for categorical variables, bold values indicate $p<0.05$.

ADL (27.3 vs 11.2), participated more often in scheduled daily activities ( $92 \%$ vs. $33 \%$ ), and used antileptics (18\% vs $1 \%$ ), psycholeptics ( $29 \%$ vs $11 \%$ ), psychoanaleptics ( $10 \%$ vs $6 \%$ ) more often than elderly persons from the general population.

HA-ID participants who provided only data on sleep-wake rhythms ( $n=201$ ), were more independent (ADL scores; 23.4 vs 29.9 ), scored less often above cut off for depressive symptoms (10\% vs $18 \%$ ), used less often anitepileptics (12\% vs $22 \%$ ), and smoked more often ( $28 \%$ vs $20 \%$ ) when compared to HA-ID participants who provided both data on sleep-wake rhythms and sleep-estimates $(\mathrm{n}=300)$.

\subsubsection{Sleep-wake rhythms}

Table 2 describes the IS, IV, RA, M10 and L5 of elderly persons with ID and elderly persons from the general population and the group comparison. The fully adjusted model showed the sleepwake rhythms of elderly persons with ID to be significantly less stable (IS: $\beta=-0.20, p<0.001$ ) and more fragmented (IV: $\beta=0.19$, $p<0.001$ ) than that of elderly persons from the general population. Also, elderly persons with ID were significantly less active during the day (M10: $\beta=-0.24, p<0.001$ ) and more active during the night (L5: $\beta=0.12, p<0.001$ ), resulting in a lower relative amplitude (RA: $\beta=-0.17, p<0.001$ ) when compared to elderly persons from the general population.

\subsubsection{Sleep characteristics}

Table 2 describes the sleep characteristics of elderly persons with ID and elderly persons from the general population and the group comparison. In the fully adjusted model, elderly persons with ID slept on average 60.09 min longer than elderly persons from the general population (TST: $7.4 \mathrm{~h}$ vs $6.39 \mathrm{~h}, p<0.001$ ), and lay awake $48.3 \mathrm{~min}$ longer after sleep onset (WASO: $118.59 \mathrm{~min}$ vs $69.36 \mathrm{~min}$, $p<0.001$ ).

Short sleep (TST $<6 \mathrm{~h}$ ) was more prevalent in elderly persons from the general population compared to elderly persons with ID ( $30.2 \%$ vs $20.7 \%$ respectively). In elderly persons with ID with short sleep, short sleep was more severe when compared to short sleep in elderly persons from the general population as shown by the TST being 14 min shorter $(p<0.006)$. Night waking (WASO $>90 \mathrm{~min}$ ) was more prevalent in elderly persons with ID (66.3\% vs $38.4 \%$, OR
$8.39, p<0.001)$. Night waking was more severe in elderly persons with ID with night waking as shown by the WASO being $36 \mathrm{~min}$ longer ( $p<0.001$ ), when compared to elderly persons from the general population with night waking. For elderly persons with ID, the chance of having at least one sleep problem was a 2.5 -fold higher than for elderly from the general population having at least one sleep problem. Correcting for covariates did not change these results.

\section{Discussion}

In the current study, we compared objectively measured sleepwake rhythms and sleep of elderly persons with ID with that of a representative sample of elderly persons from the general population. We found that the sleep-wake rhythms of elderly persons with ID were more fragmented and less stable than that of elderly persons in the general population. Elderly persons with ID sleep longer, but have more trouble maintaining sleep as resembled by the higher prevalence of people experiencing night waking. Sleep problems seem to be more severe in elderly persons with ID. When corrected for demographics, mental health indicators and lifestyle characteristics, the differences in sleep-wake rhythms between the two groups remained. The results of our study show that the sleepwake rhythms and sleep characteristics seen in elderly persons with ID are not solely the result of aging as is seen in the general population.

The population of elderly persons with ID who receive organized care is best described by a distinctive combination of characteristics that might all together affect their sleep-wake rhythms and sleep. The intellectual disability itself might seem an obvious factor, though the mechanism of ID on the sleep-wake rhythms is largely unknown. Syndromes associated with ID like Down syndrome, Smith-Magenis and Angelman syndrome, are known for their atypical sleep-wake rhythms and high prevalence of sleep problems [39-41]. In addition, health conditions like diabetes, epilepsy and psychopathology are common in elderly persons with ID [15] and are associated with sleep problems [7]. The medications commonly used in these conditions, for instance antidepressants, antiepileptics and antipsychotics, also impact the sleep-wake rhythms [1,6,7]. 
Table 2

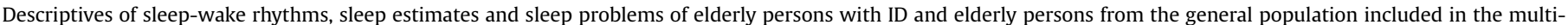
variate regression analyses and test-results for group.

\begin{tabular}{|c|c|c|c|c|c|c|c|c|}
\hline \multirow[b]{2}{*}{ Sleep-wake rhythms } & \multirow{2}{*}{$\begin{array}{l}\text { Elderly persons with ID } \\
\mathrm{N}=501\end{array}$} & \multirow{2}{*}{$\begin{array}{l}\begin{array}{l}\text { Elderly persons } \\
\text { from general population }\end{array} \\
\mathrm{N}=1734\end{array}$} & \multicolumn{6}{|c|}{ Test results for Elderly persons with ID } \\
\hline & & & Beta & $\begin{array}{l}\text { Standard } \\
\text { Error of Beta }\end{array}$ & $\begin{array}{l}\text { Standardized } \\
\text { Beta }\end{array}$ & $p$-value ${ }^{a}$ & $\mathrm{R}^{2}$ & $\mathrm{CI}$ \\
\hline IS, (mean, sd) & $0.70(0.17)$ & $0.80(0.10)$ & -0.08 & 0.01 & -0.20 & $<\mathbf{0 . 0 0 1}$ & 0.03 & {$[-0.10,-0.07]$} \\
\hline IV, (mean, sd) & $0.56(0.26)$ & $0.42(0.13)$ & 0.08 & 0.01 & 0.19 & $<0.001$ & 0.02 & {$[0.06-0.10]$} \\
\hline RA, (mean, sd) & $0.64(0.15)$ & $0.71(0.10)$ & -0.05 & 0.01 & -0.17 & $<\mathbf{0 . 0 0 1}$ & 0.01 & {$[-0.06,-0.03]$} \\
\hline L5, (mean, sd) & $11.24(6.20)$ & $9.24(4.07)$ & 1.38 & 0.30 & 0.12 & $<0.001$ & 0.01 & {$[0.80,1.97]$} \\
\hline M10, (mean, sd) & $49.28(10.07)$ & $53.99(3.71)$ & -3.532 & 0.36 & -0.24 & $<\mathbf{0 . 0 0 1}$ & 0.04 & {$[-4.24,-2.82]$} \\
\hline Sleep & $\mathrm{N}=300$ & $\mathrm{~N}=1728$ & & & & & & \\
\hline TST, hours (mean, sd) & $7.40(1.70)$ & $6.39(0.84)$ & $60.09 \mathrm{~min}$ & 4.55 & 0.34 & $<\mathbf{0 . 0 0 1}$ & 0.07 & {$[51.16,69.02]$} \\
\hline WASO, minutes (mean, sd) & $\begin{array}{l}118.59(61.39) \\
\mathrm{N}=300\end{array}$ & $\begin{array}{l}69.36(25.34) \\
N=1728\end{array}$ & $\begin{array}{l}48.28 \mathrm{~min} \\
\text { Beta }\end{array}$ & $\begin{array}{l}2.57 \\
\text { Standard } \\
\text { Error of Beta }\end{array}$ & $\begin{array}{l}0.48 \\
\operatorname{Exp}(b)\end{array}$ & $\begin{array}{l}<\mathbf{0 . 0 0 1} \\
p \text {-value }\end{array}$ & $\begin{array}{l}0.14 \\
\text { Nagelkerke } \mathrm{R}^{2}\end{array}$ & $\begin{array}{l}{[43.25,53.32]} \\
\text { CI } \operatorname{Exp}(\mathrm{b})\end{array}$ \\
\hline Short sleep (TST<6 h), \% & 20.7 & 30.2 & -0.78 & 0.18 & 0.46 & $<\mathbf{0 . 0 0 1}$ & 0.09 & {$[0.32,0.66]$} \\
\hline Night waking (WASO>90 min), \% & 63.0 & 17.7 & 2.13 & 0.18 & 8.39 & $<\mathbf{0 . 0 0 1}$ & 0.19 & {$[6.28,14.79]$} \\
\hline at least 1 sleep problem, \% & 67.3 & 38.8 & $\begin{array}{l}0.87 \\
\text { Beta }\end{array}$ & $\begin{array}{l}0.14 \\
\text { Standard } \\
\text { Error of Beta }\end{array}$ & $\begin{array}{l}2.45 \\
\text { Standardized } \\
\text { Beta }\end{array}$ & $\begin{array}{l}\mathbf{0 . 0 1 1} \\
p \text {-value }\end{array}$ & $\begin{array}{l}0.12 \\
\mathrm{R}^{2}\end{array}$ & $\begin{array}{l}{[1.61,3.56]} \\
\mathrm{CI}\end{array}$ \\
\hline $\begin{array}{l}\text { TST in hours in short sleep } \\
\text { (mean, sd) }\end{array}$ & $\begin{array}{l}N=62 \\
5.13(0.80)\end{array}$ & $\begin{array}{l}\mathrm{N}=523 \\
5.39(0.50)\end{array}$ & -14.10 & 5.10 & -0.09 & 0.006 & 0.01 & {$[-24.14,-4.06]$} \\
\hline $\begin{array}{l}\text { WASO in minutes in night waking } \\
\text { (mean, sd) }\end{array}$ & $\begin{array}{l}\mathrm{N}=189 \\
150.39(54.72)\end{array}$ & $\begin{array}{l}N=306 \\
111.60(17.95)\end{array}$ & 35.94 & 5.09 & 0.37 & $<\mathbf{0 . 0 0 1}$ & 0.08 & {$[25.95,45.93]$} \\
\hline
\end{tabular}

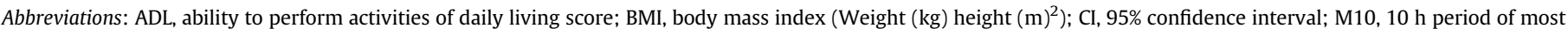

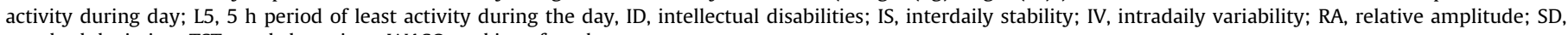
standard deviation; TST, total sleep time; WASO, waking after sleep onset.

${ }^{a}$ Multivariate linear regression analyses mutually adjusted for group, sex, age, daily activities, ADL score, BMI, current smoking (yes/no), depressive symptoms (yes/no). Elderly persons from general population are reference. $p<0.05$.

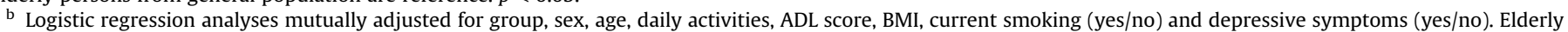
persons from general population are reference. bold values indicate $p<0.05$.

The care dependency is another feature that distinguishes elderly persons with ID from elderly persons from the general population. All participants with ID in our study sample received organized care and $95.3 \%$ lived in a care facility. The daily schedule of care in group homes entails nearly all facets of the life of the resident; from dressing, eating and from being assisted around bedtime to activities during the day. In nursing home residents as well as in elderly persons with ID, care dependency is shown to affect the sleep by lowering the subjective sleep duration and increasing the time spend in bed [7,42].

This care dependency might explain the longer total sleep duration in elderly persons with ID when compared to that of elderly persons from the general population. These care schedules are pragmatic but do not account for the personal preference of the residents. Nor is the schedule adjusted to the experienced sleep pressure, or tiredness, of the resident. Based on the ADL item "transfer from/to bed", $20 \%$ of our sample of elderly persons with ID receives verbal or physical assistance by professional caregivers with getting in and out of bed. This might lead to longer time in bed, and more opportunity for sleep thus resulting in longer total sleep time, but also more opportunity to lay awake.

The effect of care dependency is not limited to sleep alone; elderly persons with ID depend on third parties like care professionals to undertake all sorts of activities during the day, such as walking and crafts. These activities induce the accumulation of sleep pressure, or sleepiness, needed for falling asleep and maintaining sleep [43]. Elderly persons with ID are known to be little physically active and show high levels of sedentary behaviour $[44,45]$. Sedentary behaviour is in turn related to insomnia and sleep problems [46], whereas more activity was related to higher stability and less fragmentation of the sleep-wake rhythms in elderly persons with ID [6].

The impact of sleep disturbances seen in elderly persons with ID is illustrated by the poor sleep quality, as indexed by the long WASO in our sample. The WASO is on average $47 \mathrm{~min}$ longer in elderly persons with ID than in elderly persons from the general population. Another indicator of sleep quality is sleep efficiency, the percentage of time in bed spend sleeping. Based on the TST and WASO, people with ID spend at least $10 \mathrm{~h}$ in bed, compared to $7 \mathrm{~h}$ in elderly persons without ID. This results in a sleep efficiency of at most 78\% for people with ID, compared to $86 \%$ in elderly persons from the general population, whereas an efficiency of minimal $80 \%$ is considered adequate. Thus, longer sleep duration does not automatically translate to a good sleep quality in elderly persons with ID.

In addition, although we did not measure all facets of sleep we consider the night waking as excessively long. When night waking is assessed in the context of insomnia, a cut-off for WASO of 30-66 min is applied [47,48]. In our sample, elderly persons with ID lie awake 24 min more. For diagnosing insomnia, the duration, frequency and the subjective experience of complaints are required. Due to the cognitive or communicative limitations, reporting a subjective experience in elderly persons with ID is challenging. Therefore, objective criteria to diagnose insomnia in people with ID are explored [49]. Nevertheless, our findings of very substantial unrecognized sleep problems in this population is highly relevant.

\subsection{Strengths \& limitations}

The current study is the first to compare actigraphy data of elderly persons with ID with a representative sample of elderly persons from the general population. The sleep-wake rhythms and sleep were measured with valid and reliable measurements for measuring sleep. The findings must be generalized with caution as the study sample is almost representative of all elderly persons with ID receiving care in the Netherlands [19].

The two study populations were not assessed for a comparative study. This resulted in a lack of overlapping covariates between the two studies. As a result, we were not able to fully correct for comorbidities (eg, neurodegenerative disorders like dementia) and medication use that might influence sleep. The Actiwatch is 
considered a valid and reliable measure of sleep, but it is less capable to measure waking accurately [23]. Elderly persons with ID specifically have a tendency to be awake, while lying still in bed. Consequently, the TST might be overestimated, and the WASO might have been underestimated in this study. The current study addressed at a limited number of sleep outcomes; TST and WASO. Additionally, sleep onset latency and sleep efficiency are important sleep characteristics. Sleep onset latency was defined differently in both studies, which made a comparison less reliable. Nonetheless, our findings might be an underestimation of the sleep-wake rhythms and sleep problems seen in elderly persons with ID.

\subsection{Future research and clinical relevance}

Future research on sleep in people with ID should focus on describing the sleep-wake rhythms and sleep and the development with age in adults with ID using objective and well validated measurements like actigraphy and polysomnography. Secondly, identifying objective cut-off scores and definitions for sleep-wake rhythms and sleep problems in elderly persons with ID are required and can be of great benefit in diagnosing sleep problems in this population.

The findings of the current study indicate the need for more attention on sleep problems in elderly persons with ID. Improving the sleep quality by bedtime scheduling and educating caregivers was found to be effective [50], but availability of evidence based interventions for sleep problems in adults and elderly persons with ID are limited [51,52]. Scheduling bedtimes based on the preference and sleep-wake rhythms of the individual residents, instead of the work schedule of the professional care givers could be a starting point.

\section{Conclusion}

We found that the sleep-wake rhythms of elderly persons with ID is more fragmented and less stable when compared to that of elderly persons in the general population. Even though elderly persons with ID sleep longer, they have more trouble maintaining sleep as resembled by a higher prevalence of people experiencing night waking. We conclude that the characteristics of sleep-wake rhythms and sleep in elderly persons with ID who receive organized care are not merely the result of aging as seen in elderly persons from the general population. The results suggest that the combination of ID, comorbidities, medication use and care dependency might explain the characteristics. The sleep quality in elderly persons with ID is low and might be a precursor for underlying sleep problems. A better understanding of sleep and clear definitions of sleep problems in adults, and specifically elderly persons, with ID is needed. These serve as a starting point to improve the quality of sleep in this population and to diminish health problems related to a disruption of sleep.

\section{CRediT authorship contribution statement}

Mylène N. Böhmer: Conceptualization, Data curation, Investigation, Formal analysis, Methodology, Project administration, Writing - original draft. Alyt Oppewal: Supervision, Writing - review \& editing. Patrick J.E. Bindels: Supervision, Writing - review \& editing. Henning Tiemeier: Methodology, Resources, Writing review \& editing. Eus J.W. van Someren: Supervision, Writing review \& editing. Dederieke A.M. Festen: Supervision, Writing review \& editing.

\section{Acknowledgement}

The authors thank the HA-ID consortium and the Rotterdam Study for providing the data for this project. The authors thank Desana Kocevska of Erasmus MC, University Medical Center Rotterdam, Department of Epidemiology for her assistance during this project. All authors made substantial contributions to the design of this study and/or were involved in the interpretation of the data. All authors drafted the work, and reviewed and revised the manuscript critically. All authors approved the final version to be published.

\section{Funding}

This research did not receive any specific grant from funding agencies in the public, commercial, or not-for-profit sectors.

\section{Conflict of interest}

None declared.

The ICMJE Uniform Disclosure Form for Potential Conflicts of Interest associated with this article can be viewed by clicking on the following link: https://doi.org/10.1016/j.sleep.2020.10.019.

\section{References}

[1] Van de Wouw E, Evenhuis HM, Echteld MA. Prevalence, associated factors and treatment of sleep problems in adults with intellectual disability: a systematic review. Res Dev Disabil 2012;33:1310-32. https://doi.org/10.1016/ j.ridd.2012.03.003.

[2] Didden R, Curfs LM, Van Driel S, et al. Sleep problems in children and young adults with developmental disabilities: home-based functional assessment and treatment. J Behav Ther Exp Psychiatr 2002;33:49-58. https://www. sciencedirect.com/science/article/pii/S0005791602000125?via\%3Dihub.

[3] Didden R, Korzilius H, Van Aperlo B, et al. Sleep problems and daytime problem behaviours in children with intellectual disability. J Intellect Disabil Res 2002;46:537-47. https://doi.org/10.1046/j.1365-2788.2002.00404.x.

[4] Richdale AL, Baker EK. Sleep in individuals with an intellectual or developmental disability: recent research reports. Curr Dev Dis Rep 2014;1:74-85. https://doi.org/10.1007/s40474-014-0010-x.

[5] Surtees ADR, Oliver C, Jones CA, et al. Sleep duration and sleep quality in people with and without intellectual disability: a meta-analysis. Sleep Med Rev 2018;40:135-50. https://doi.org/10.1016/j.smrv.2017.11.003.

[6] Maaskant M, Van de Wouw E, Van Wijck R, et al. Circadian sleep-wake rhythm of older adults with intellectual disabilities. Res Dev Disabil 2013;34: 1144-51. https://doi.org/10.1016/j.ridd.2012.12.009.

[7] Van de Wouw E, Evenhuis HM, Echteld MA. Objective assessment of sleep and sleep problems in older adults with intellectual disabilities. Res Dev Disabil 2013;34:2291-303. https://www.sciencedirect.com/science/article/pii/ S0891422213001650.

[8] Luik AI, Zuurbier LA, Hofman A, et al. Stability and fragmentation of the activity rhythm across the sleep-wake cycle: the importance of age, lifestyle, and mental health. Chronobiol Int 2013;30:1223-30. https://doi.org/10.3109/ 07420528.2013 .813528$.

[9] Ohayon MM, Carskadon MA, Guilleminault C, et al. Meta-analysis of quantitative sleep parameters from childhood to old age in healthy individuals: developing normative sleep values across the human lifespan. Sleep 2004;27: 1255-73. https://doi.org/10.1093/sleep/27.7.1255.

[10] Van Someren EJ. Circadian rhythms and sleep in human aging. Chronobiol Int 2000;17:233-43. https://www.ncbi.nlm.nih.gov/pubmed/10841205.

[11] Van Someren EJ, Riemersma RF, Swaab DF. Functional plasticity of the circadian timing system in old age: light exposure. Prog Brain Res 2002;138: 205-31. https://doi.org/10.1016/S0079-6123(02)38080-4.

[12] Swaab DF, Van Someren EJ, Zhou JN, et al. Biological rhythms in the human life cycle and their relationship to functional changes in the suprachiasmatic nucleus. Prog Brain Res 1996;111:349-68. https://doi.org/10.1016/s00796123(08)60418-5.

[13] Moore RY. Suprachiasmatic nucleus in sleep-wake regulation. Sleep Med 2007;8(Suppl 3):27-33. https://doi.org/10.1016/j.sleep.2007.10.003.

[14] Li J, Vitiello MV, Gooneratne NS. Sleep in normal aging. Sleep Med Clin 2018;13:1-11. https://doi.org/10.1016/j.jsmc.2017.09.001.

[15] Hermans H, Evenhuis HM. Multimorbidity in older adults with intellectual disabilities. Res Dev Disabil 2014;35:776-83. https://doi.org/10.1016/ j.ridd.2014.01.022.

[16] Schoufour JD, Oppewal A, Van Der Maarl HJK, et al. Multimorbidity and polypharmacy are independently associated with mortality in older people with intellectual disabilities: a 5-year follow-up from the HA-ID study. Am J 
Intellect Dev Disabil 2018;123:72-82. https://doi.org/10.1352/1944-7558123.1.72.

[17] O'dwyer M, Peklar J, Mccallion P, et al. Factors associated with polypharmacy and excessive polypharmacy in older people with intellectual disability differ from the general population: a cross-sectional observational nationwide study. BMJ Open 2016;6:e010505. https://doi.org/10.1136/bmjopen-2015010505.

[18] Mccarron M, Swinburne J, Burke E, et al. Patterns of multimorbidity in an older population of persons with an intellectual disability: results from the intellectual disability supplement to the Irish longitudinal study on aging (IDS-TILDA). Res Dev Disabil 2013;34:521-7. https://doi.org/10.1016/ j.ridd.2012.07.029.

[19] Hilgenkamp TI, Bastiaanse LP, Hermans H, et al. Study healthy ageing and intellectual disabilities: recruitment and design. Res Dev Disabil 2011;32: 1097-106. https://doi.org/10.1016/j.ridd.2011.01.018.

[20] Ikram MA, Brusselle G, Ghanbari M, et al. Objectives, design and main findings until 2020 from the Rotterdam Study. Eur J Epidemiol 2020;35:483-517. https://doi.org/10.1007/s10654-020-00640-5.

[21] Folstein MF, Folstein SE, Mchugh PR. Mini-mental state - practical method for grading cognitive state of patients for clinician. J Psychiatr Res 1975;12: 189-98. https://doi.org/10.1016/0022-3956(75)90026-6.

[22] Ancoli-Israel S, Cole R, Alessi C, et al. The role of actigraphy in the study of sleep and circadian rhythms. Sleep 2003;26:342-92. https://doi.org/10.1093/ sleep/26.3.342.

[23] Van de Wouw E, Evenhuis HM, Echteld MA. Comparison of two types of Actiwatch with polysomnography in older adults with intellectual disability: a pilot study. J Intellect Dev Disabil 2013;38:265-73. https://doi.org/10.3109/ 13668250.2013.816274.

[24] Kushida CA, Chang A, Gadkary C, et al. Comparison of actigraphic, polysomnographic, and subjective assessment of sleep parameters in sleepdisordered patients. Sleep Med 2001;2:389-96. https://doi.org/10.1016/ s1389-9457(00)00098-8.

[25] Rowe M, Mccrae C, Campbell J, et al. Actigraphy in older adults: comparison of means and variability of three different aggregates of measurement. Behav Sleep Med 2008;6:127-45. https://www.tandfonline.com/doi/pdf/10.1080/ 15402000801952872 ? needAccess = true.

[26] Van Someren EJ, Swaab DF, Colenda CC, et al. Bright light therapy: improved sensitivity to its effects on rest-activity rhythms in Alzheimer patients by application of nonparametric methods. Chronobiol Int 1999;16:505-18. https://www.tandfonline.com/doi/pdf/10.3109/07420529908998724? needAccess=true.

[27] Ensrud KE, blackwell TL, Ancoli-Israel S, et al. Sleep disturbances and risk of frailty and mortality in older men. Sleep Med 2012;13:1217-25. https:// doi.org/10.1016/j.sleep.2012.04.010.

[28] Ensrud KE, Blackwell TL, Redline S, et al. Sleep disturbances and frailty status in older community-dwelling men. J Am Geriatr Soc 2009;57:2085-93. https://doi.org/10.1111/j.1532-5415.2009.02490.x.

[29] Magee CA, Caputi P, Iverson DC. Short sleep mediates the association between long work hours and increased body mass index. J Behav Med 2011;34: 83-91. https://doi.org/10.1007/s10865-010-9287-3.

[30] Van den Berg JF, Luijendijk HJ, Tulen JH, et al. Sleep in depression and anxiety disorders: a population-based study of elderly persons. J Clin Psychiatr 2009;70:1105-13. https://doi.org/10.4088/JCP.08m04448.

[31] Mahoney FI, Barthel DW. Functional evaluation: the Barthel index. Md State Med J 1965;14:61-5. https://www.ncbi.nlm.nih.gov/pubmed/14258950.

[32] Hermans H, Beekman AT, Evenhuis HM. Prevalence of depression and anxiety in older users of formal Dutch intellectual disability services. J Affect Disord 2013;144:94-100. https://doi.org/10.1016/j.jad.2012.06.011.

[33] Rush AJ, Gullion CM, Basco MR, et al. The inventory of depressive Symptomatology (IDS): psychometric properties. Psychol Med 1996;26:477-86. https://doi.org/10.1017/s0033291700035558.

[34] Roeden J. Signaallijst voor Zwakzinnigen. 1989.
[35] Schoonhoven M. Depressie bij mensen met een verstandelijke handicap: nadere research met de signaallijst depressie voor zwakzinnigen. In: Hogeschool F, editor. Tilburg; 2001.

[36] Bruce B, Fries JF. The Stanford health assessment Questionnaire: dimensions and practical applications. Health Qual Life Outcome 2003;1:20. https:// doi.org/10.1186/1477-7525-1-20.

[37] Radloff LS. The CES-D Scale: a self-report depression scale for research in the general population. Appl Psychol Meas 1977;1:385-401. https://doi.org/ 10.1177/014662167700100306.

[38] Beekman AT, Deeg DJ, Van Limbeek J, et al. Criterion validity of the Center for Epidemiologic Studies Depression scale (CES-D): results from a communitybased sample of older subjects in The Netherlands. Psychol Med 1997;27: 231-5. https://doi.org/10.1017/s0033291796003510.

[39] Gimenez S, Videla L, Romero S, et al. Prevalence of sleep disorders in adults with Down syndrome: a comparative study of self-reported, actigraphic, and polysomnographic findings. J Clin Sleep Med 2018;14:1725-33. https:// doi.org/10.5664/jcsm.7382.

[40] Spruyt K, Braam W, Curfs LM. Sleep in Angelman syndrome: a review of evidence. Sleep Med Rev 2018;37:69-84. https://doi.org/10.1016/ j.smrv.2017.01.002.

[41] Trickett J, Oliver C, Heald M, et al. Sleep in children with Smith-Magenis syndrome: a case-control actigraphy study. Sleep 2020;43. https://doi.org/ 10.1093/sleep/zsz260.

[42] Tabali M, Ostermann T, Jeschke E, et al. Does the care dependency of nursing home residents influence their health-related quality of life?-A cross-sectional study. Health Qual Life Outcome 2013;11. https://doi.org/10.1186/1477-752511-41.

[43] Borbely AA, Daan S, Wirz-Justice A, et al. The two-process model of sleep regulation: a reappraisal. J Sleep Res 2016;25:131-43. https://doi.org/ $10.1111 /$ jsr.12371.

[44] Hilgenkamp TI, Reis D, Van Wijck R, et al. Physical activity levels in older adults with intellectual disabilities are extremely low. Res Dev Disabil 2012;33:477-83. https://www.sciencedirect.com/science/article/pii/ S0891422211003908.

[45] Melville CA, Oppewal A, Schafer Elinder L, et al. Definitions, measurement and prevalence of sedentary behaviour in adults with intellectual disabilities - a systematic review. Prev Med 2017;97:62-71. https://doi.org/10.1016/ j.ypmed.2016.12.052.

[46] Yang Y, Shin JC, Li D, et al. Sedentary behavior and sleep problems: a systematic review and meta-analysis. Int J Behav Med 2017;24:481-92. https:// doi.org/10.1007/s12529-016-9609-0.

[47] Lichstein KL, Durrence HH, Taylor DJ, et al. Quantitative criteria for insomnia. Behav Res Ther 2003;41:427-45. https://doi.org/10.1016/s0005-7967(02) 00023-2.

[48] Nano M, Fonseca P, Overeem S, et al. Lying awake at night: cardiac autonomic activity in relation to sleep onset and maintenance. Front Neurosci 2020;13. https://doi.org/10.3389/fnins.2019.01405.

[49] Van den Broek AAM, Festen DAM, Tan IY, et al. What's in a name? Op zoek naar de definitie van insomnie bij mensen met een verstandelijke beperking. Tijdschrift voor Artsen voor Verstandelijk Gehandicapten 2018;36(4). https:// nvavg.nl/wp-content/uploads/2019/01/Magazine_NVAVG_NR4_website.pdf.

[50] Hylkema T, Vlaskamp C. Significant improvement in sleep in people with intellectual disabilities living in residential settings by non-pharmaceutical interventions. J Intellect Disabil Res 2009;53:695-703. https://doi.org/ 10.1111/j.1365-2788.2009.01177.x.

[51] Priday LJ, Byrne C, Totsika V. Behavioural interventions for sleep problems in people with an intellectual disability: a systematic review and meta-analysis of single case and group studies. J Intellect Disabil Res 2017;61:1-15. https:// doi.org/10.1111/jir.12265.

[52] Shanahan PJ, Palod S, Smith KJ, et al. Interventions for sleep difficulties in adults with an intellectual disability: a systematic review. J Intellect Disabil Res 2019;63:372-85. https://doi.org/10.1111/jir.12587. 